\title{
Коллаборация как форма разрешения противоречий конкуренции
}

\author{
Ли Дэли ${ }^{1 *}$, Владимир Останин ${ }^{2}$ \\ ${ }^{1}$ Дальневосточный федеральный университет, Владивосток, Россия \\ ${ }^{2}$ Владивостокский филиал Российской таможенной академии, Владивосток, Россия
}

\author{
Информация о статье \\ Поступила в редакичию: \\ 06.06.2019 \\ Принята \\ к опубликованию: \\ 10.04.2020
}

УДК 33.011

JEL A10; L22; O10

\section{Ключевые слова}

конкуренция, коллаборация, рыночные структуры, интегральные формы фермерских хозяйств, организация, кооперация, противоречия конкуренции, формы разрешения рыночных взаимосвязей

\section{Keywords:}

competition, collaboration, market structures, integral forms of farms, organization, cooperation, competition differences, forms of resolving market relationships

\begin{abstract}
Аннотация
В статье проведен анализ ключевых понятий рыночной экономики. Конкуренция является важным и необходимым атрибутом взаимосвязей в рыночной экономике. В ходе исследования определено современное состояние теории конкуренции при создании международных интегральных форм организации бизнеса. Выявлено, что конкуренция является важным и необходимым атрибутом взаимосвязей в рыночной экономике, но при этом не единственным. Доказано, что отношения коллаборации могут находить свою естественную нишу в новых интегральных формах кооперации среди сообщества фермерских хозяйств России и Китая.
\end{abstract}

\section{Collaboration as a Form to Adjust the Competition Differences}

Deli Li, Vladimir Ostanin

\section{Abstract}

The theoretical foundations of the modern theory of competition and collaboration in the concept of the dialectical interconnection theory in the market economy have been described, the key concepts of "competition" and "collaboration" have been analyzed. Competition, as well as collaboration, are essential and important attributes of interconnections in the market economy. The topicality of this scientific issue can be seen in the fact that such fundamental concepts as "competition" and "collaboration", as well as their dialectical unity, have not been correctly described in the modern scientific literature. The advantages of the competition relations are often exaggerated, and the negative aspects are downgraded in the scientific literature.

The investigation found the current state of the competition theory in creating international integrated forms of business administration. Competition is not the only form of relationship that can be established between the business entities. The advantages of developing collaborative relationships more thoroughly manifest themselves in the formation of the organization integral forms. It has been proved that collaborative relationships can find their natural niche in the new integral forms of cooperation among the farms communities of Russia and China.

\footnotetext{
*Автор для связи: li.de@dvfu.ru

DOI: https://dx.doi.org/10.24866/2311-2271/2019-4/5-16
} 
«Конкуренщия - настолько необходимо, коллаборация - насколько возможно».

\section{Введение}

Экономическая природа фирмы продолжает оставаться предметом научных поисков. Следует принять в качестве очевидного, что индивидуальные хозяйствующие субъекты не играют важной роли в производстве национального богатства. Таким основным элементом в процессе воспроизводства становится предприятие, фирма, обладающие внутренней структурой, целостностью и системностью. Тем не менее, вопрос остаётся открытым, каким образом были сформированы предпосылки, чтобы на место хозяйствующих индивидуальных хозяйствующих предпринимателей пришли организации, фирмы, предприятия. Современное состояние теории организации и предпринимательства характеризуется наличием различных концептов понятий «фирма», «предприятие».

Это широкое разночтение общеизвестных понятий может быть объяснено тем, что фирма, предприятие понимались как общеизвестное и понятное. Проблемы возникают сразу же, как только начинают наполнять эти термины концептом.

Например, под фирмой понимается институциональная форма (институт) с его необходимыми атрибутами. Фирма представляется как юридический конструкт, организация, обладающая соответствующей организационно-правовой формой.

Организация той или иной формы ведения предпринимательской деятельности, процессы реорганизации, слияний, поглощений, создания интегральных форм бизнеса являются проблемами как непосредственно самой практики бизнеса в процессе поиска наиболее оптимальных форм организации бизнеса, так и теории организации. Важный вклад в теорию фирмы сделал Ф. Найт [1], Р. Коуз [2], что явилось отправным этапом в проведении дальнейших исследований в направлении поиска оптимальной структуры рынка $[3,4]$.

\section{Доказательство тезиса}

Чтобы понять природу взаимосвязей между составляющими некоторую целостность экономических образований в различных формах, например, картелей, синдикатов, трестов других социально-экономических ассоциаций, следует первоначально понять природу элементарного звена, т.е. фирмы. Первое прорывное исследование природы фирмы было выполнено Френком Найтом. Ключевым моментом в процессе организации фирмы Ф. Найт видел неопределённость, выделяя её от страхуемой неопределённости или риска. Неопределённость невозможно устранить, однако существуют способы снизить степень опасности от ее воздействия. К ним Ф. Найт относил знания о будущем, которые люди могут приобретать с помощью научных исследований, а также накопленного в прошлом опыта. Это сопряжено с издержками, расходованием ресурсов. Второй способ раскрывается в аккумуляции неопределённостей «вместе посредством разных форм крупномасштабной организации» [1], что также требует не только расходования ресурсов, но неизбежную при этом потерю индивидуальной свободы.

Индивиды (работники) рассматривают потерю индивидуальной свободы 
как проигрыш, другие (менеджеры) усматривает выигрыш от того, что приобретают контрольные функции власти. Контроль над будущим также рассматривается как фактор, который позволит снизить неопределённость самого будущего.

Все эти отмеченные издержки ресурсов и потерю свободы следует отнести к той цене, которая сопряжена с организацией производственных работников в некоторое целое, т.е. хозяйствующее предприятие, организацию. Таким образом, объединение индивидуумов в организацию сопряжено с издержками ресурсов, потерей индивидуальной свободы, одновременно распределяя риски на всех индивидов, которые уже объединены в организацию. При этом риски не распределяются равномерно в организации между составляющими организацию индивидами, здесь может отмечаться как концентрация, так и распыление риска. Высший уровень ответственности лежит на очень узкой группе людей организации, как правило, они являются носителями властных функций. Положительным благом организации также следует считать то, что в результате объединения усилий, потенций каждого индивида, целое, т.е. организация, становится больше суммы её частей, что выявляется в эффекте эмерджентности.

Р. Коуз подверг критике взгляды Ф. Найта на природу фирмы. Его основные возражения сводились к тому, что люди принимают на себя риск, не требуют от других осуществлять над ними функции контроля. У Ф. Найта эти условиях взаимоувязаны. Далее Р. Коуз утверждает, что ценовая система не нуждается в организации, т.е. фирме, как институте для решения проблемы риска и его распределения. Цена уже несёт в себе плату за риск. Но у Р. Коуза причиной трансформации индивидуальные работников в организацию, т.е. в фирму осуществляется под необходимостью экономии трансакционных издержек. Становится понятным, что ценовой механизм, координация внутри рыночной стихии не становится бесплатным. Фирма продолжает находиться в рыночной среде, однако внутри фирмы как такового рынка нет, ибо индивиды связаны контрактами, что даёт основание судить о природе фирмы как о некоторой совокупности контрактов, придающей её также и целостность.

Рыночный механизм, ранее действующий до образования фирмы между индивидами, замещается механизмом координации на основе требований, обязанностей, установленного уставом фирмы порядком. По А. Маршаллу фирма, как организация, становится четвёртым фактором производства. Дж. Б. Кларк предпринимателя наделяет функцией координации, Ф. Найти вводит функцию менеджера, Дж.Э. Робинсон в фирме, как организации, обнаруживает «островки сознательной власти в этом океане бессознательной конкуренции, подобно сгусткам масла, сбивающимся в бадье с пахтой» [2].

В исследованиях Морис Добба природа фирмы объясняется системой разделения труда. Фирма возникает в силу усложнения системы разделения труда, ибо дальнейшая экономическая дифференциация создаёт надобность в некоторых интегрирующих силах, без действия которых система превратилась бы в хаос. Если за пределами фирмы производство и распределение подчинено движению цен, то внутри фирмы рыночные сделки устранена, роль сложной рыночной системы, координирующая деятельность уже всей системы, перешла к руководителю-координатору в лице предпринимателя [2], организующего производство уже на принципах планомерности (die Planmäßigkeit - нем.), как сознательно поддерживаемой пропорциональности, по выражению К. Маркса. 
Признавая важность фактора цен в трансформации индивидуальных производителей в организацию, фирму либо иную производительную ассоциацию, не следует преувеличивать роль цены, как интегрирующей силы в дифференцированной рыночной экономике, как это делает Р. Коуз. Производительные ассоциации могут создавать свои интегральные организации под воздействием уже не только механизма цен, либо экономии трансакционных издержек, но и экономии ресурсов, что становится возможным уже на основе солидаризации, или коллаборации, предпринимателей, фирм, ибо это позволяет преодолевать разрушительные тенденции жёсткой конкуренции. Именно эти производительные интегральные формы организации, становясь «островками сознательной власти» не столько замещают механизм цен, сколько замещают частично отношения конкуренции отношениями коллаборации. Следовательно, критика Р. Коуза выводов Мориса Добба в этом случае просто не достигает цели [2].

Конкуренция, если не отягощать этот термин нехарактерными для этого понятия характеристиками, не вводить некоторые дополнительные термины, которые будут скорее уводить исследователя от генеральной линии раскрытия экономической природы и потенциала конкуренции, будет соответствовать одновременно неэффективному состоянию экономической системы. Первый, кто на высоком теоретическом уровне корректно аргументировал свою позицию, был А.О. Курно. В его работе «Исследования математических принципов теории богатства» (1838 г.) анализу была подвергнута простейшая рыночная структура - дуополия. А.О. Курно в качестве исходных посылок полагал, что каждая из двух фирм будет производить продукции в соответствии со своими производственными возможностями. Их итоговых объём производства будет определён на пересечении этих двух кривых, а точка их пересечения будет соответствовать равновесному состоянию по Курно. Каждый производитель будет правильно полагать объемы выпуска конкурента, и исходя из этого будет стремиться максимизировать прибыль. Так как фирмы могут манипулировать только ценами, ибо производственный потенциал должен однозначно использоваться полно, то любое изменение цены в большую или меньшую сторону будет вести в конечном счёте к потере дохода. Следовательно, «равновесие по Курно» имеет место быть при некооперативном поведении игроков, что характерно для конкуренции. Конкуренты находятся в состоянии борьбы за максимально возможную прибыль. При таком сочетании объёмов выпуска фирм на момент времени ни у одной фирмы не будет стимула для изменений. Устанавливается и соответствующая равновесная цена, которая будет ниже монопольной цены, однако эта цена будет выше цены, которая установилась бы при некооперативной, жёсткой конкуренции. Эта цена, следовательно, является равновесной, при любом её отклонении происходит её возврат в первоначальное равновесное состояние.

Следует отметить, что модель А.О. Курно может быть расширена и на большее число фирм. Позднее в теории игр состояние равновесия по Курно было проанализировано Дж. Нэшем. Суть положения несколько по-иному интерпретировало поведение игроков. Исходили из того положения, что каждый игрок принимает наилучшее решение, исходя из действий противника. Но так как любое действие оппонента приводит к ухудшению его положения, то ни у одного не появляется стимула изменить это уже сложившееся состояние. Модель некооперативного равновесия Курно, где в основу графической интерпретации положены объёмы производства, когда ни один производитель не меняет 
своей производственной позиции, приводит к тем же результатам, если проблему рассматривать в теории игр, как это сделал Нэш, который тоже формирует равновесное оптимальное состояние, или равновесие по Нэшу, но уже в теории игр. Но так приоритет следует отдать А. Курно, то модель Нэша может быть охарактеризована как модель равновесия Нэша в модели Курно.

Это даёт основания трактовать данное состояние рынка как состояние неэффективного равновесия, или «институциональную ловушку конкуренции». Вводя в научный оборот данное понятие с соответствующим научным термином, мы исходим из методологического положения академика В.М. Полтеровича, который вообще понимал под концептом понятия «ловушка» состояние неэффективного равновесия. «Под институциональными ловушками понимаются неэффективные, но устойчивые институты, или нормы поведения, возникающие в реформировании экономики» [6], Состояние неэффективности отношений конкуренции с позиций целостной экономической системы, а не только её отдельных акторов, была доказана первоначально А.О. Курно, а с использованием метода теории игр - Дж. Нэшем.

В данной статье авторы исходят из положения, что конкуренция есть не только состояние и характеристика рынка, но и процесс, т.е. движение. Как состояние конкуренция есть внешняя форма объективного, или онтологического, противоречия. Сущностная форма любого онтологического противоречия, по теории В.В. Вяккерева, есть «самодвижение». $[7,8,9]$ Конкуренция как борьба за ограниченные ресурсы, есть движение, как выражение существующего противоречия. Свои формы разрешения это онтологическое противоречие находит в развитии форм своего существования. Его крайние формы лежат в границах полного отрицания конкуренции, ориентируемой на поглощение, подавление и выдавливание экономических агентов с конкурентного рынка, так и полного отрицания самого факта борьбы, или в терминологии К. Маркса, планомерности (die Planmäßigkeit- нем.), как сознательно поддерживаемой пропорциональности [10].

Теория онтологических противоречий и форм их разрешения позволяет делать вывод, что формы разрешения этого противоречия конкуренции лежат в движении как рыночных, так и планомерных форм. Однако истина никогда не лежит в крайностях, т.е. как в жесткой форме конкуренции, ориентированной на подавление оппонента, так и в абсолютном отрицании конкуренции, или планомерности. Диалектика рыночных взаимосвязей укладывается в логику разрешения диалектических противоречий бытия отношений обмена, в которых обнаруживается как моменты конкуренции, так и «островков сознательной власти».

Так как онтологические противоречия есть противоречия самих взаимосвязей как рыночных, так и планомерных обменов, то и формы движения, развития связей обмена неотъемлемы от самых взаимосвязей. Сама взаимосвязь внутренне противоречива, что на поверхности этого явления обнаруживается в форме противоположностей конкуренции и её антипода, т.е. планомерности. Каждая сторона этого противоречия внимает в себя «свое иное», по Г.В.Ф. Гегелю. При этом одна из сторон является всегда отрицающей другую. Проблема теории диалектического противоречия видится в том, что невозможно однозначно определить, какая сторона получает доминирование, хотя изначально, в соответствии с методологией Г.В.Ф. Гегеля этой доминирующей стороной является именно отрицающая сторона. Поэтому проблема отрицания планомер- 
ности конкуренцией или отрицание конкуренции планомерностью является проблемой исторической одновременно. Каждая форма на определенном этапе социально-экономического, политического, институционального развития может доминировать, порождая свои естественные для себя формы осуществления. Этот переход одной формы в другую был исследован великим русским экономистом, философом, физиологом А.А. Богдановым [11, 12].

Конкуренция не приемлет формирование сознательно поддерживаемой целостности оппонента. Конкуренция есть по определению экономическая борьба за выживание, за лидерство, неизбежно ведёт к поглощению, подавлению оппонента. В этой области скорее господствует стихия, которую саму следует рассматривать как «бессознательное сознательного». Ибо у человека, социального сообщества нет коллективного разума, как некоторого органического вместилища разума. Коллективные органы, способные представлять эти «островки сознательной власти» у человечества отсутствуют. Коллективные органы есть в колониях полипов, которые способны формировать, как отмечал Г. Спенсер, «коллективные желудки».

Рынок, даже если его наделяют характеристиками регулируемости, всегда будет тяготеть к конкуренции акторов в борьбе за больший охват рынка, получению преференций за счет как рыночных, так и нерыночных факторов. Рынок всегда будет оставаться некоторой стихией, действуя в соответствии со своей природой хаотически, «...слепо, со страшной силою своей темной, хаотичной, но бесчисленной и бесконечной армии элементов. Чтобы победить её, человечество должно организоваться само в могучую армию. И оно организуется в ряду веков, образуя трудовые коллективы, от маленьких родовых общин первобытной эпохи до современного сотрудничества сотен миллионов людей, ими ещё неосознанного, но вполне реального. ... Самое глубокое различие, какое известно нам в природе, это - различие между стихийностью и сознательностью, между слепым действием сил природы и планомерными усилиями людей» [13].

Коллаборация изначально предопределяется формирующимся или формируемым органическим целом, которое представлено общественной структурой, или общественным организмом. И это органическое целостное образование становится уже больше простой суммы её частей. Однако этот прибавок активностей органического целого имеет в своей природе уже реализованный потенциал взаимосвязи частей суммы в органы целого. Как отмечает А. Богданов, «наличные активности соединяются с меньшею потерею, чем противостоящие им сопротивления. ... Там, где сталкиваются активности и сопротивления, практическая сумма, воплощенная в реальных результатах, зависит от способа сочетания тех и других; и для целого эта сумма увеличивается на той стороне, на которой соединение более стройно или «гармонично», заключает меньше «противоречий». Это и означает более высокую организованность» [13].

Следовательно, мы имеем достаточно оснований для вывода о том, что созданные и создаваемы рыночные структуры, являются не более, как частным случаем институциональных образований вообще, но с меньшей степенью внутренней сложностью и организованностью по сравнению с социально планомерно организованными системами. Социально организованные системы эволюционируют от хаотически оформленных структур к общественно упорядоченным системам, в структуре которых можно обнаруживать уже «островки 
сознательной власти».

Утверждение о планомерно организованных общественных системах как обладающих более высокой активностью, а, следовательно, эффективностью, далеко не бесспорно. Сознательное в образование предполагает то, что власть осознаёт свои цели, политика вырабатывает адекватные располагаемым ресурсам механизмы и инструменты. В этом случае реализуемая на практике планомерность имеет своим следствием усложнение качества структуры и организации. Во вновь формируемом целом по своему потенциалу суммативное целое будет больше своих частей.

Однако, как свидетельствует практика становления и развития общественных институтов, сознательно организуемое целое может носить и дезорганизованный характер. В этом случае, как отмечал в свои исследования И. Кант, целое может быть и меньше своих частей, в данном случае по своему экономическому потенциалу. В первом случае взаимосвязи и отношения конкуренции, в которых преобладает мотив сопротивления, будет меньше положительного эффекта от взаимодействия, когда элементы в большей мере способны извлекать комплементарные эффекты от этих взаимосвязей.

Как показывает практика в объективной реальности не существует как идеальной положительной организованности, так и отрицательной дезорганизованности. «...Даже наилучше устроенное сотрудничество не может быть свободно от всяких, хотя бы минимальных, внутренних помех и несогласованностей, наилучше конструированная машина - от внутренних трений, и т.п.» [13]. Потенциал экономических агентов в конкурентной среде подвергается дифференциации, имеет место процесс селекции, когда выживает более приспособленный. Однако это локальное выживание и его индивидуальное укрепление осуществляется за счёт подавления потенциала противника. Здесь мы имеем в лучшем случае исход с нулевой суммой, в худшем - с отрицательной суммой.

Коллаборация же отличается уже не подавлением оппонентов, а извлечение положительного эффекта от потенциала взаимосвязей. В этом случае имеет место процесс формирования более жизнеспособной среды не отдельного актора, а целого. Активности элементов в последнем случае не направлены друг против друга, а действуют согласованно, или организованно, в направлении формирования более эффективного целого. Потенциал целого, в том числе общественного хозяйственного образования, например, ассоциации производителей, ассоциации фермерских хозяйств, что отличает их от простой механической совокупности, становится больше суммы потенциалов отдельных хозяйств. Простое суммативное целое предполагает, что вектор потенциала фермерских хозяйств может быть разнонаправленным, разную направленность своих усилий, целеполаганий. Однако наличие «островков сознательной воли» целого, например, ассоциации фермерских хозяйств, этот хаос трансформирует в упорядоченное единство. Тем самым мы можем утверждать, что сама упорядоченность хозяйствующих фермерских хозяйств становится производительным фактором, позволяющим увеличивать свой производственный потенциал. Коллаборативное целое всегда обладает большим экономическим потенциалом по сравнению с суммативным экономическим образованием, если только само ассоциативное целое не подвергается дезорганизующим воздействиям.

Эмпирический поиск более эффективных форм организации интегральных форм фермерских хозяйств предполагает усложнение внутренних взаимо- 
связей, позволяющих за счёт кооперации извлекать больший положительный эффект. Этот процесс поиска и использования положительных организационных сил может осуществляться как стихийно, так и в результате сознательного действия руководящего органа, который, собственно, и представляет эти «островки сознательной власти».

Сознательно, тем не менее, не ведет с необходимостью к тому результату, что итогом может стать исключительно организующая функция. Сознательные островки иерархической власти, воплощающие ошибочно выбранные направления, формы, масштабы организации интегральных форм, могут нести и дезорганизующую функцию. Более того, затрагивая традиционные уклады с их устоявшими институтами, обычаями, силами привычек исполнителей, у его акторов возникают шоки при переходе к стихии рынка, формируются пики «шоковой терапии» в результате дезорганизующей роли и характера осуществляемых структурных преобразований. Это имело место в России, в Китае в результате планомерно реализуемых мероприятий по невыверенной и непродуманной политики сознательно осуществляемых реформ политического руководства этих стран. Особый ущерб от реализации подобной непродуманной политики был нанесен как бывшей РСФСР в период насильственной коллективизации и раскулачивании крестьянства как класса, так и в КНР в период «Большого скачка (1958-1960 гг.)». (По прошествии лет можно констатировать, что в Китай пережил крупную сочиальную катастрофу в середине прошлого столетия, что в итоге привело не к ожидаемому процветанию страны, богатства его граждан и укреплению государства, а к гибели народных масс, истощению национальных ресурсов, необоснованной политизации всего китайского общества. Аграрный по своему укладу Китай был подвергнут, практически насильственно, модернизачии сельского хозяйства за счёт создания народных коммун. Так называемая «коммунизачия основных отраслей» за «три года упорного труда» не привела к «10000 лет счастья», а обернулась полным социальным фиаско. Это касалось выплавки стали в глинобитных примитивных печах, число которых достигало 700 тысяч с более чем 100 тысячами занятыли рабочими на выплавке стали из руды, истребления воробьёв с иелью сохранения урожая, реквизиции зерна у крестьян, что привело к голоду. По некоторым данным этот социальный «эксперимент унёс жизнь около 45 млн человек) $[14,15]$.

Теоретически ответ на процессы общественной структурной организации дал в своих трудах А.А. Богданов. Человеческая деятельность представляет собой всегда «результат столкновения разных организационных процессов. ... Если общества, классы, группы разрушительно сталкиваются, дезорганизуя друг друга, то именно потому, что каждый такой коллектив стремится организовать мир и человечество для себя, по-своему. Это результат отдельности, обособленности организующих сил, результат того, что еще не достигнуты их единство, их общая, стройная организация. Это борьба организационных форм. ... В термине «производство» скрыто понятие организующего действия. И мы сделаем эту формулу точнее: организация внешних сил природы, организация человеческих сил, организация опыта...

Итак, все интересы человечества - организационные. А отсюда следует: не может и должно быть иной точки зрения на жизнь и на мир, кроме организационной. И если это ещё не сознаётся, то только потому, что мышление людей до сих пор не выбилось вполне из оболочек фетишизма, окутавших его на 
пути развития» [11].

Недостаток конкуренции как общественного института видится в том, что его конкуренты имеют одну цель - максимизировать экономический эффект, подавляя конкурента. Но находясь одновременно в одних и тех же ограниченных ресурсах и возможностях для расширенного своего собственного воспроизводства они обречены на борьбу. Тем самым они, находясь во взаимной борьбе, составляют дезорганизующую комбинацию. Как отмечает А.А. Богданов по отношению двух конкурентов, цели у них «одинаковые»: один желает для себя того, чего для себя желает другой; но, разумеется, организации они вдвоём не составляют, потому что общей цели у них нет. Слово «общая» означает не сходство, а совпадение. При конкуренции одинаковые цели не совпадают, а расходятся: они разнонаправленно ориентированы. Организованность достигается постольку, поскольку направление активности, выражаемое целью, тождественно для обоих сотрудников. «...Организованное целое оказалось на самом деле практически больше простой суммы своих частей, но не потому, чтобы в нём создавались из ничего новые активности, а потому, что его наличные активности соединяются с меньшей потерею, чем противостоящие им сопротивления. Наш мир есть вообще мир разностей; только разности напряжений энергии проявляются в действии, только эти разности имеют практическое значение. Там, где сталкиваются активности и сопротивления, практическая сумма, воплощённая в реальных результатах, зависит от способа сочетания тех и других; и для целого эта сумма увеличивается на той стороне, на которой соединение более стройно или "гармонично", заключает меньше "противоречий". Это и означает более высокую организованность» [16].

Если эти новые интегральные хозяйственные объединения, созданные с целью повышения эффективности производства, переработки сельскохозяйственной продукции, её хранению, транспортировки и реализации населению, позволяют добиваться снижения как трансформационных, так и трансакционных издержек, что в конечном счёте свидетельствует о реализации основного экономического закона - закона экономии времени - то эту новую структурный организацию можно считать успешной.

Ключевым признаком этой организации, и её отличия от дезорганизации, является то, что интересы ни одного не были ущемлены. Общий прирост эффективности всего нового интегрального объединения и его отдельных членов стал возможен не за счет перераспределения и суммирования эффектов отдельных фермерских хозяйств, а приросту общего результате сверх сумм отдельных хозяйств. Тем самым суммативное образование, которое таким оставалось до объединения в интегральные формы, приобретает частично признаки организма, т.е. признаки целого. Целое же уже больше суммы своих частей, а прежде его составляющие отдельные фермерские хозяйства при объединении образуют органы единого целого. Если прежде до объединения отдельные фермерские хозяйства сталкивались в конкурентной борьбе, преодолевая сопротивление конкурентов и затрачивая при этом дополнительные ресурсы на борьбу, то в объединении с присущим им «островкам сознательной власти» их отношения более гармонизированы, противоречия частично разрешены, а само интегральное объединения, например, в форме холдинга, выявляет более высокую организованность и эффективность, в том числе, Парето эффективность. Можно вслед за А.А Богдановым констатировать, что в стремлении повысить эффективность хозяйствования у людей «нет иной деятельности, кроме органи- 
зационной, нет иных задач, кроме организационных. ... все интересы человечества - организационные. А отсюда следует: не может и не должно быть иной точки зрения на жизнь и мир, кроме организационной. И если это ещё не сознаётся, то только потому, что мышление людей до сих пор не выбилось из оболочек фетишизма, окутавших его на пути развития» [16].

\section{Выводы}

Конкуренция, возникшая из разделения труда и борьбы человека против человека, начинает утрачивать свои разъединяющие начала и влияние. Будучи моментом диалектического противоречия взаимодействия людей, в процессе совместного производства условий своего собственного бытия трансформируется в свою противоположность, которая на поверхности экономического явления может быть представлена как кооперация, взаимопомощь, или коллаборация. Эта форма уже будет находиться на более высокой ступени организации хозяйственной жизни, включая в свои структуры «островки сознательной власти». Однако в соответствии с законами диалектической логики, это отрицание будет осуществлено одновременно с удержанием прежнего, положительного, т.е. включением тех моментов диалектической логики, которую Г.В.Ф. Гегель назвал «снятие» (или das Aufcheben - нем.)

Отрицание конкуренции с образованием новых организационных форм в фермерских хозяйствах, которые начинают интегрироваться как горизонтально, так и вертикально, осуществляется не абсолютно, а сохраняя переходные формы, например, хозяйственную самостоятельность, формы собственности. Коллаборация отношений в новых интегральных формах может представляться в артелях, кооперативах, картелях, холдингах, различных формах товариществ, образованных в соответствии с действующими законодательными актами на территориях сопредельных государств. Предлагаемое в статье обоснование необходимости поиска более эффективных форм интеграции фермерских хозяйств на трансграничных территориях есть только одна из необходимых сторон экономической интеграции. Сами по себе интегральные формы организации охватывают более обширные области человеческого общего жития, по Серафиму Соровскому, а именно: психологию, социологию, политику, культуру и т.д. Однако сформировав экономические предпосылки, новая созданная интегральная форма будет с необходимостью достраивать эти недостающие ей звенья, тем самым становясь органической целостностью.

Наконец, природа фирмы рассматривалась с позиций снижения и распределения риска (Ф. Найт), снижения трансакционных издержек (Р. Коуз), состоянием технологии и машинного производства (Теория делового предприятия Т. Веблена). В статье делается вывод, что природа современного предприятия может рассматриваться с позиций отношений коллаборации, которая разрешает противоречия конкуренции. Данное суждение позволяет сделать дополнительный вывод о том, что результаты данного исследования могут способствовать расширению поля научных интересов в направлении поиска конкретных хозяйственных форм хозяйственной интеграции, а также создания эконометрических моделей оптимизации предпринимательских структур в сельском хозяйстве. 


\section{Список источников / References}

1. Найт Ф.Х. Риск, неопределённость и прибыль. Москва, Дело, 2003. 360 с. [Nayt F.Kh. Risk, neopredelennost' i pribyl' [Risk, uncertainty and profit]. Moscow, Delo Publ., 2003. 360 p.]

2. Коуз Р. Фирма, рынок и право. Москва, Новое издательство, 2007. 224 с. [Kouz R. Firma, rynok i parvo. [Firm, market and law]. Moscow, New Publishing House, 2007. 224 p.]

3. Машунин Ю.К. Теория, математическое моделирование и прогнозирование развития рынка. Известия ДВФУ. Экономика и управление, 2016, №4. сс. 18-40. [Mashunin Yu.K. Teoriya, matematicheskoye modelirovaniye i prognozirovaniye razvitiya rynka. [Theory, mathematical modeling and forecasting of market development]. Izvestiya DVFU. E`konomika i upravlenie = The Bulliten of FEFU. Economics and Management, 2016, no. 4, pp. 18-40.]

4. Кошкин В.И., Кретов С.И. Основы политической экономии солидаризма. Москва, ЛЕНАНД, 2017. 400 с. [Koshkin V.I., Kretov S.I. Osnovy politicheskoy ekonomii solidarizma. [Fundamentals of Political Economy of Solidarity]. Moscow, LENAND Publ., 2017. 400 p.]

5. Савицкая Е.В. Экономический анализ современных рынков: учеб. Пособие / Е.В. Савицкая; Гос. Ун-т - Высшая школа экономики, 2-е изд. М.: Изд. Дом ГК ВШЭ, 2008. 208c. [Savitskaya, Ye.V. Ekonomicheskiy analiz sovremennykh rynkov: ucheb. Posobiye. [Economic analysis of modern markets: textbook Allowance]. M.: Izd. Dom GK VSHE, 2008. 208p.]

6. Полтерович В.М. Институциональные ловушки и экономический рост. [Polterovich V.M. Institutsional'nyye lovushki i ekonomicheskiy rost. [Institutional Traps and Economic Growth]. Available at: file://C:/Users/USER/Desktop/99-04-020-polterovich-v-minstitutsionalnye-lovushki-i-ekonomicheskie-reformy-rossiyskaya-ekon-shkola-m-199842s.pdf. (accessed 21.03.2019).

7. Онтология и теория познания в 2 т. Том 1. Основы онтологии: учебник для академического бакалавриата / Ф. Ф. Вяккерев [и др.] М. : Издательство Юрайт, 2018. 322 c. [Ontologiya i teoriya poznaniya v 2 t. Tom 1. Osnovy ontologii : uchebnik dlya akademicheskogo bakalavriata / F. F. Vyakkerev [i dr]. [Ontology and the theory of knowledge in 2 volumes. Volume 1. Fundamentals of ontology: a textbook for academic undergraduate / F.F. Vyakkerev [et al.] M. : Izdatel'stvo Yurayt, 2018. 322 p.]

8. Вяккерев Ф.Ф. Философия конфликта. Философские основания конфликтологии / Ф.Ф. Вяккерев. Владивосток, Изд-во Дальневост. Ун-та, 2004. 84c. [Vyakkerev F.F. Filosofiya konflikta. Filosofskiye osnovaniya konfliktologii / F.F. Vyakkerev. [Ontology and the theory of knowledge]. Vladivostok, Izd-vo Dal'nevost. Un-ta, 2004. 84p.]

9. Глухов В.В., Останин В.А. Теоретические аспекты конфликтно-компромиссных решений существующих экономических противоречий. Новая наука: Теоретический и практический взгляд, 2017, Т 1, № 3. сc. 132-139. [Glukhov V.V., Ostanin V.A. Teoreticheskiye aspekty konfliktno-kompromissnykh resheniy sushchestvuyushchikh ekonomicheskikh protivorechiy. [Theoretical aspects of conflict-compromise solutions to existing economic contradictions]. Novaya nauka: Teoreticheskiy i prakticheskiy vzglyad. 2017. T. 1. № 3. pp. 132-139.]

10. Маркс К. Критика Готской программы. К. Маркс, Ф. Энгельс. Сочинения, Т. 19, Издание 2-е, Государственное издательство Политической литературы, М., 1961. сс. 9-36. [Marks K. Kritika Gotskoy programmy. [Criticism of the Gotha Program]. State Publishing House of Political Literature. M., 1961. pp. 9-36.]

11. Богданов А.А. Тектология: Всеобщая организационная наука В 2-х кн.: Кн. 1. / Редкол. Л.И.Абалкин (отв. ред.) и др. / Отделение экономики АН СССР. Ин-т экономики АН СССР, М.: Экономика, 1989. 304 с. [Bogdanov A.A. Tektologiya: Vseobshchaya organizatsionnaya nauka. V 2-kh .: Kn. 1. [Tectology: General Organizational Science]. Department of Economics, USSR Academy of Sciences. Institute of Economics, USSR 
Academy of Sciences. M.: Economics, 1989. 304 p.]

12. Богданов А.А. Тектология: Всеобщая организационная наука. В 2-х кн.: Кн. 2. / Редкол. Л.И.Абалкин (отв. ред.) и др. / Отделение экономики АН СССР. Ин-т экономики АН СССР. М.: Экономика, 1989. 351 c. [Bogdanov A.A. Tektologiya: Vseobshchaya organizatsionnaya nauka. [Tectology: General Organizational Science] Department of Economics, USSR Academy of Sciences. Institute of Economics, USSR Academy of Sciences. M.: Economics, 1989. 351 p.]

13. Богданов А. Очерки организационной науки. [Bogdanov A. Ocherki organizatsionnoy nauki. [Bogdanov A. Essays on organizational science.] Available at: http://www.uic.unn.ru/pustyn/lib/bogdanov.ru.html (accessed 21.03.2019).

14. Большой скачок Мао Цзэдуна. [Bol'shoy skachok Mao TSzeduna. [Mao Zedong's Great Leap Forward]. Available at: http://jj-tours.ru/adds/blog-china/2016-05-16-great-leapforward.html (accessed 23.03.2019).

15. Большой китайский «скачок». [Bol'shoy kitayskiy «skachok». [The Great Chinese Leap Forward]. Available at: https://diletant.media/articles/30444853/ (accessed 23.03.2019).

16. Богданов А.А. Единство организационной точки зрения. [Bogdanov A.A. Yedinstvo organizatsionnoy tochki zreniya. [Unity of organizational point of view]. Available at: http://www.uic.unn.ru/pustyn/lib/bogdanov.ru.html (accessed 23.03.2019).

\section{Сведения об авторах / About authors}

Останин Владимир Анатольевич, доктор экономических наук, профессор, Владивостокский филиал Российской таможенной академии. 690034 Россия, г. Владивосток, ул. Стрелковая, 16в. Тел: 89502957821.E-mail: ostaninva@yandex.ru

Vladimir A. Ostanin, Doctor of Economics, Professor, Vladivostok branch of the Russian Customs Academy. 16v, Strelkovaya Street, Vladivostok, Russia 690034. Tel: 89502957821.

E-mail: ostaninva@yandex.ru

Ли Дэли, аспирант кафедры менеджмента, Школа экономики и менеджмента, Дальневосточный федеральный университет. 690922 Россия, г. Владивосток, о-в Русский, кампус ДВФУ, корпус G. E-mail: li.de@dvfu.ru

Li Deli, Postgraduate Student, Department of Management, School of Economics and Management, Far Eastern Federal University. Building G, FEFU campus, Russky Island, Vladivostok, Russia 690922. Tel: 89247338003.E-mail: li.de@dvfu.ru 